\title{
Serum and urine amino acid profiles of captive cheetahs (Acinonyx jubatus)
}

\author{
Adrian Stephen Wolferstan Tordiffe ${ }^{1,2^{*}}$ and Lodewyk Jacobus Mienie ${ }^{3}$ \\ ${ }^{1}$ Department of Paraclinical Sciences, Faculty of Veterinary Science, University of Pretoria, Private Bag X04, \\ Onderstepoort, 0110, South Africa. \\ ${ }^{2}$ National Zoological Gardens of South Africa, P.O. Box 754, Pretoria, 0001, South Africa \\ ${ }^{3}$ Centre for Human Metabolomics, Faculty of Natural \& Agricultural Sciences, Private Bag X6001, North-West \\ University, Potchefstroom, 2520, South Africa. \\ *corresponding author - adrian.tordiffe@up.ac.za, tel +27 125298368 \\ ASW Tordiffe ORCID - 0000-0001-5416-3153 \\ LJ Mienie ORCID - 0000-0003-0860-5285
}

\begin{abstract}
Background: Cheetahs in captivity are frequently afflicted by chronic disease conditions that are rare in their free-ranging counterparts and in other felids. To date, clear pathophysiological mechanisms for some of these diseases have not been established.

Objective: In order to better understand these conditions in this species, we have adopted a systems biology approach to cheetah metabolism, with the hope of generating new hypotheses for future research.

Methods: As part of a comprehensive metabolome, we determine the serum $(\mathrm{N}=42)$ and urine $(\mathrm{N}=26)$ amino acid profiles of apparently healthy captive cheetahs, housed at the AfriCat Foundation in Namibia, using GCMS and LC-MS-MS.

Results: A total of 36 serum and 38 urine amino acids were identified and quantified. Glutamine was detected in the serum at the highest mean concentration $(1624 \mu \mathrm{mol} / \mathrm{L})$ followed by alanine $(771.9 \mu \mathrm{mol} / \mathrm{L})$, arginine $(669.8$ $\mu \mathrm{mol} / \mathrm{L})$ and glycine $(478.7 \mu \mathrm{mol} / \mathrm{L})$. Serum glycine, hydroxyproline, prolylproline, proline and serine concentrations declined significantly with age. Arginine was excreted at the highest mean concentration (740 $\mu \mathrm{mol} / \mathrm{L})$, followed by glutamine $(437.1 \mu \mathrm{mol} / \mathrm{L})$, alanine $(397.1 \mu \mathrm{mol} / \mathrm{L})$ and serine $(331.1 \mu \mathrm{mol} / \mathrm{L})$. The fractional excretion of cystine was by far the highest at $21.92 \%$, followed by hydroxylysine (6.34\%), prolinehydroxyproline $(5.49 \%)$ and $\alpha$-aminopimelic acid (4.89\%). Both urinary glycine and proline-hydroxyproline concentrations decreased significantly with age. None of the serum or urine amino acid concentrations differed significantly between males and females.

Conclusion: This study provides some foundational information on the serum and urine amino acid profiles of healthy captive cheetahs.
\end{abstract}

Keywords Amino acids, Cheetahs, Acinonyx jubatus, Serum, Urine, Fractional excretion. 


\section{INTRODUCTION}

In captivity, cheetahs are often afflicted by chronic disease conditions of the gastrointestinal tract, kidneys and other organs that rarely affect their free-ranging counterparts or other felid species (Munson et al. 1999, 2005). Low genetic heterogeneity, stress, lack of exercise and nutritional factors have been suggested as possible underlying causes for these disorders, but clear evidence supporting such associations remains unclear. In order to better understand the pathophysiology of these conditions in this species, we have adopted a systems biology approach to cheetah metabolism, with the hope of generating new hypotheses for future research. To-date we have compared the serum fatty acid profiles of captive and free-ranging cheetahs (Tordiffe et al. 2016) and have documented the urine organic acid profiles of captive individuals (Tordiffe et al. 2017). This approach has already led to several new avenues for future investigation.

The free serum amino acid pool is derived primarily from: the digestion of endogenous proteins and peptides, absorbed into the circulation after being sloughed or secreted from the gastro-intestinal tract; dietary protein digested and absorbed from the gastro-intestinal tract; and intracellular protein turnover or degradation (Stipanuk and Caudill 2013). Serum concentrations of amino acids appear to be tightly controlled by homeostatic mechanisms and remain fairly constant after initial postprandial fluctuations in healthy adult humans (Milsom et al. 1979), but have been shown to vary significantly during growth, disease and various catabolic conditions (Armstrong and Stave 1973; Blazer-Yost and Jezyk 1979; Hanssen et al. 1989; Chan et al. 2009; Azuma et al. 2012; Okame et al. 2015). Serum or plasma amino acids are influenced by dietary protein and amino acid intake (Longenecker and Hause 1959; Hall et al. 2003). Unlike other macronutrients, amino acids cannot be stored when provided in excess. Dietary amino acids can be synthesised into proteins, but these are only produced in quantities necessary for specific functions. Surplus amino acids therefore have to be metabolised and this has important implications in carnivores, where a significant proportion of the diet is made up of protein.

The pattern of urinary excretion of amino acids varies tremendously between different mammalian species (Datta and Harris 1952; Evered 1967), but tends to be more uniform within a species (Albanese and Orto 2012). Urinary amino acid concentrations are frequently evaluated in suspected cases of inborn-errors of metabolism, where dramatic amino-acidurias are apparent. The excretion patterns are however more subtly affected by diet and age, while modified patterns of excretion have been documented in various disease states (Albanese and Orto 2012).

Serum or plasma amino acid profiles have been reported in domestic kittens fed purified diets (Rogers and Morris 1979; Hargrove et al. 1988) and in adult cats fed commercial diets (Heinze et al. 2009). A single metabolomic study that included plasma amino acid quantification in domestic cats, only recently appeared in the literature (Deng et al 2014). Only limited serum and urinary amino acid profiles of non-domestic felid species have, to our knowledge, been reported (Datta and Harris 1952; Tordiffe et al. 2012). A number of studies have focused on the excretion of felinine and isovalthine, two sulphur-containing amino acid excreted in the urine of a few felid species (Hendriks et al. 1995). The biological significance of these sulphur amino acids remains unclear, but it is speculated that they may act as precursors to certain pheromones (Tarttelin et al. 1998).

In order to develop a better understanding of the unique metabolic processes and nutritional requirements of these animals we determined the serum and urine amino acid profiles of captive cheetahs in an untargeted fashion using gas chromatography mass spectrometry (GC-MS) and liquid chromatography tandem mass spectrometry (LCMS-MS).

\section{MATERIALS AND METHODS}

\section{Samples}

Captive cheetahs, aged between 3 and 13 years, housed at the AfriCat Foundation in Namibia were immobilized via remote injection dart (Daninject, Denmark) with medetomidine hydrochloride (Medetomidine 20mg/ml, Kyron Laboratories Pty LTD, South Africa) in combination with either zolazepam/tiletamine (Zoletil®, Virbac, South Africa) or midazolam (Midazolam 50mg/ml, Kyron Laboratories Pty LTD, South Africa) and butorphanol (Butorphanol 50mg/ml, Kyron Laboratories Pty LTD, South Africa), after being starved for 24 to 48 hours. Blood samples were collected within 15 minutes of immobilization from 42 adult cheetahs (25 males and 17 females), while urine samples were available within the same time frame from 26 of these individuals (16 males and 10 females). These animals were housed in large enclosures $\left(>1000 \mathrm{~m}^{2}\right)$ covered by natural vegetation and fed diet 
consisting primarily of donkey meat supplemented with a combination of vitamins and minerals (FeliCal@ and FeliVit ${ }^{\circledR}$, Kyron Laboratories, South Africa).

The blood samples were collected aseptically from a jugular vein with a $20 \mathrm{ml}$ syringe and 18 gauge needle. The blood was transferred into $6 \mathrm{ml}$ BD Vacutainer® tubes (Becton, Dickinson and Company, South Africa) and allowed to clot for 40 minutes on ice. Samples were then centrifuged at $3500 \mathrm{rpm}$ for five minutes, the serum was pipetted off into $1.8 \mathrm{ml}$ Cryovials ${ }^{\circledR}$ (Thermo Scientific, South Africa) and immediately frozen at $-20{ }^{\circ} \mathrm{C}$.

Urine was collected by direct urethral catheterization using a 6 FG dog urinary catheter into a 20ml syringe. After centrifugation at $3500 \mathrm{rpm}$ for 5 minutes, the supernatant was placed into $1.8 \mathrm{ml}$ Cryovials ${ }^{\circledR}$ (Thermo Scientific, South Africa, 1401) and immediately frozen at $-20{ }^{\circ} \mathrm{C}$. The samples were transported to the laboratory on dry ice and then kept frozen at $-80^{\circ} \mathrm{C}$ until analysis.

\section{Urine creatinine, specific gravity and fractional excretion}

In the laboratory, urine was thawed and allowed to warm to room temperature. The urine creatinine concentrations were determined by an enzymatic method on an Indiko Clinical Chemistry Analyzer (Thermo Scientific, South Africa) using the manufacturer's kit and instructions. The urine specific gravity (SG) was measured with a hand held refractometer (RHC-200), calibrated with distilled water.

The fractional excretion of amino acids provides an indication of the degree of urinary excretion versus reabsorption relative to creatinine and in this study was calculated using the standard equation:

$$
\text { Fractional amino acid excretion }=100 \times \frac{\text { Urinary amino acid [ ] } x \text { Serum creatinine [] }}{\text { Urinary creatinine [ ] } x \text { Serum amino acid [] }}
$$

\section{Reagents}

The EZ:faast TM amino acid analysis kits were purchased from Phenomenex Inc. (Torrence, CA, USA). Additional reagents and amino acid standards (DLAla, LAla, LaIle, DaIle, LLeu, DLeu, LVal, DVal, DLNva, LIso, and DLIle), were purchased from Sigma-Aldrich (St Louis, MO, USA) and stable isotope amino acid mixtures (Metabolomics amino acid mix standard) were obtained from Cambridge Isotope Laboratories Inc (Tewksbury, MA, USA).

\section{Amino acid analysis using GC-MS}

The gas chromatography - mass spectrometry analysis of the serum and urine amino acids was conducted on a Hewlett Packard HP6890 series GC system with an Agilent 5973N Mass selective detector fitted with an EI ion source, an Agilent Technologies 7683 autosampler and a 7683B injector. The GC system was fitted with a Phenomenex GC FocusLiner liner for HP, split/splitless, w/wool, single taper, $4 \mathrm{~mm}$ ID x $78.5 \mathrm{~mm} \mathrm{~L} \mathrm{x} 6.3 \mathrm{~mm}$ OD (part number AG0 4680), and a Phenomenex Zebron EZ AAA amino acid GC column, $10 \mathrm{~m} \mathrm{x} 0.25 \mathrm{~mm} x$ $0.25 \mu \mathrm{m}$ (part number CG0 7169), and an Agilent Technologies gas clean filter system (part number CP17973).

The serum and urine amino acid analyses are based on the methods prescribed in the EZ:faast TM kit, with the following modifications. 1) Stable isotope amino acid standards ( $100 \mu 1$ per sample) were added to ensure accurate quantification of the amino acids. 2) $\mathrm{NaOH}$ or $\mathrm{HCl}$ is added to the sample to adjust the $\mathrm{pH}$ to between 1.5 and 6 . 3) The final step (drying of the samples and reconstitution with reagent 6) was omitted.

Helium was used as a carrier gas at a constant flow rate of $1.3 \mathrm{~mL} / \mathrm{s}$. Two microliters of the extracts was injected in "splitless" mode with a viscosity delay of 1 second and the injector set to $250^{\circ} \mathrm{C}$. The oven was set to an initial temperature of $60{ }^{\circ} \mathrm{C}$ for $1 \mathrm{~min}$, and then increased to $110^{\circ} \mathrm{C}$ at $50^{\circ} \mathrm{C} / \mathrm{min}$, immediately followed by an increase to $185^{\circ} \mathrm{C}$ at $20^{\circ} \mathrm{C} / \mathrm{min}$, and then to $235^{\circ} \mathrm{C}$ at $25^{\circ} \mathrm{C} / \mathrm{min}$, and finally to $320^{\circ} \mathrm{C}$ at $30^{\circ} \mathrm{C} / \mathrm{min}$ for $1 \mathrm{~min}$. The MSD transfer line heater was set to $280^{\circ} \mathrm{C}$, the MS source to $230^{\circ} \mathrm{C}$, and the MS quadrupole to $150{ }^{\circ} \mathrm{C}$. Solvent delay was $3.00 \mathrm{~min}$. EMV was set to a gain factor of 1.00 . The MSD was set to scan from $40-500 \mathrm{~m} / \mathrm{z}$ with a threshold of 150 .

Standard range analysis, using the MSD ChemStation E02.00 software with a linear regression curve fit was used to calibrate the identification and quantification of the amino acids. The results were exported to Microsoft Excel® 
for further analysis. Urine amino acid concentrations were corrected using urine specific gravity (SG) as described by Miller et al (Miller et al. 2004) as follows:

Corrected concentration $=$ Raw concentration $x($ SGtarget -1.0$) /($ SGsample -1.0$)$

The SGtarget is a population mean SG, which in this study is equal to 1.054 .

\section{Arginine and citrulline quantification using LC-MS/MS}

Serum and urine arginine and citrulline were quantified using LC-MS/MS rather than GC-MS due to their thermal instability. The stable isotope mixture $(410 \mu \mathrm{l})$ was pipetted into micro-centrifuge tubes to which $10 \mu \mathrm{l}$ of serum or urine was added. The mixture was centrifuged at $13000 \mathrm{~g}$ for 20 minutes after which the supernatant was pipetted into a clean micro-centrifuge tube. The tubes were then placed in a nitrogen dryer at $65^{\circ} \mathrm{C}$ for approximately 45 minutes. Once dry, $200 \mu 13 \mathrm{~N}$ buthanolic $\mathrm{HCl}$ was added and the tubes were then capped and placed in an incubator, set at $65^{\circ} \mathrm{C}$ for 15 minutes. The tubes were then placed in a nitrogen dryer for approximately 20 minutes and once dry, $100 \mu$ l of the mobile phase (acetonitrile:water [50:50] with 1\% acetic acid) was added. The samples were then transferred to GC vials for analysis.

Citrulline and arginine was analysed on a Agilent 6420 Triple Quad MS-MS (in the ESI mode, Delta EMV=500) linked to a Agilent 1260 HPLC. Citrulline-d4 and arginine-d4 were used as internal standards. Materials were prepared as described for acylcarnitine analysis with butanol/ $\mathrm{HCl}$ as derivatization reagent. The butyl esters $(5 \mu \mathrm{l})$ was injected with direct infusion. Citrulline and arginine analyses were performed as a precursor scan in positive ion mode. Q1 is set to scan a mass $\mathrm{m} / \mathrm{z} 232.2236 .2,231.2$ and 235.2 respectively for citrulline, citrulline-d4, arginine and arginine-d4 while Q3 is set to determine product ion ion of $\mathrm{m} / \mathrm{z} 70.1$, 105.2, 70.1 and 74.3 respectively for the amino acids. The settings of the MS was as indicated in Table 5-1. Source parameters: Gas temp-280 C, Gas flow-7.5 1/min, Nebulizer-28 (psi), Capillary-3500 V

Table 1. Agilent 6420 Triple Quad MS QQQ MRM settings.

\begin{tabular}{l|ccccccccc} 
Name & ISTD & Prec Ion & Prod Ion & Dwell & Frac (V) & CE (V) & Cell Acc (V) & Polarity \\
\hline Citr-d4 & Yes & 236.2 & 105.1 & 45 & 85 & 16 & 7 & + \\
Arg-d4 & Yes & 235.2 & 74.3 & 45 & 100 & 40 & 7 & + \\
Citr & No & 232.2 & 70.1 & 45 & 94 & 28 & 7 & + \\
Arg & No & 231.2 & 70.1 & 45 & 93 & 28 & 7 & +
\end{tabular}

\section{Statistical analysis}

Variables in which more than $40 \%$ of the data points were zero were eliminated and not considered for analysis. As some cystine is reduced in urine to two cysteine molecules, the total cystine/cysteine was calculated as follows: Total cystine/cysteine $=$ cystine $[$ ] + (cysteine [ ]/2). Data was tested for normality using the D'Agostino and Pearson omnibus (K2) normality test. Spearman's rho correlation coefficients were used to evaluate the relationship between age and the various amino acid concentrations. Unpaired t-tests or Mann-Whitney U tests were used for comparisons between amino acid concentrations and other parameters in males and females. All analyses were performed with GraphPad Prism version 6.05 for Windows (GraphPad Software, La Jolla, California, USA). All statistical tests were 2-tailed and significance was defined as $\mathrm{P}<0.05$ in all cases.

\section{RESULTS}

A total of 36 serum amino acids were identified and quantified as shown in Table 2. Glutamine was detected at the highest mean concentration $(1624 \mu \mathrm{mol} / \mathrm{L})$ followed by alanine $(771.9 \mu \mathrm{mol} / \mathrm{L})$, arginine $(669.8 \mu \mathrm{mol} / \mathrm{L})$ and glycine $(478.7 \mu \mathrm{mol} / \mathrm{L})$. None of the serum amino acid concentrations differed significantly between males and females. Glycine, hydroxyproline, prolylproline, proline and serine serum concentrations declined significantly with age, but the negative correlations were relatively weak as shown in Figure 1. 
Table 2. Summary of the serum amino acid concentration data $(\mu \mathrm{mol} / \mathrm{L})$ in 42 adult cheetahs, listed in order from highest mean concentration to lowest.

\begin{tabular}{|c|c|c|c|c|c|}
\hline Amino acid & Minimum & Median & Maximum & Mean & Std. deviation \\
\hline Glutamine & 788,3 & 1492,0 & 2981,0 & 1624,0 & 567,2 \\
\hline Alanine & 317,3 & 634,5 & 1824,0 & 771,9 & 333,1 \\
\hline Arginine & 188,2 & 700,8 & 1050,0 & 669,8 & 216,6 \\
\hline Glycine & 214,8 & 410,0 & 1194,0 & 478,7 & 214,3 \\
\hline Proline & 108,4 & 213,0 & 759,5 & 266,4 & 136,2 \\
\hline Valine & 104,4 & 180,8 & 422,4 & 220,1 & 90,0 \\
\hline Serine & 119,1 & 186,2 & 419,2 & 217,3 & 79,7 \\
\hline Prolylproline & 0,0 & 173,6 & 688,0 & 197,1 & 118,9 \\
\hline Lysine & 91,6 & 158,0 & 387,7 & 187,2 & 74,9 \\
\hline Glutamic-acid & 96,7 & 144,3 & 337,4 & 173,8 & 66,7 \\
\hline Leucine & 74,2 & 138,5 & 321,0 & 166,1 & 66,1 \\
\hline Allo-Isoleucine & 70,9 & 132,3 & 317,4 & 160,1 & 66,3 \\
\hline Histidine & 83,1 & 133,4 & 304,8 & 157,3 & 59,8 \\
\hline Threonine & 78,5 & 127,7 & 345,4 & 154,2 & 67,3 \\
\hline Pyroglutamic-acid & 76,7 & 127,1 & 251,5 & 140,7 & 50,0 \\
\hline Hydroxyproline & 9,2 & 92,7 & 465,9 & 131,6 & 115,5 \\
\hline Tryptophane & 69,2 & 101,0 & 238,8 & 124,5 & 46,5 \\
\hline Ornithine & 22,4 & 70,1 & 342,5 & 108,6 & 84,0 \\
\hline Isoleucine & 35,6 & 68,4 & 182,1 & 85,6 & 36,6 \\
\hline Tyrosine & 42,5 & 73,0 & 161,1 & 83,8 & 32,3 \\
\hline Phenylalanine & 30,8 & 51,9 & 220,3 & 66,6 & 35,3 \\
\hline Methionine & 31,0 & 52,2 & 146,8 & 62,5 & 27,8 \\
\hline Asparagine & 29,6 & 53,5 & 131,3 & 61,5 & 23,1 \\
\hline Citrulline & 34,6 & 39,9 & 65,2 & 41,3 & 6,1 \\
\hline Aspartic-acid & 18,1 & 28,3 & 73,6 & 34,6 & 14,9 \\
\hline Glycine-Proline & 0,3 & 15,7 & 84,8 & 23,6 & 20,8 \\
\hline Cystathionine & 5,0 & 18,9 & 69,9 & 23,5 & 16,2 \\
\hline$\alpha$-Aminobutyric-acid & 9,2 & 18,0 & 61,3 & 21,7 & 11,5 \\
\hline Proline-hydroxyproline & 2,5 & 6,1 & 83,3 & 14,0 & 20,4 \\
\hline$\alpha$-Aminoadipic-acid & 3,8 & 6,0 & 18,4 & 7,1 & 2,9 \\
\hline Cystine & 1,5 & 4,3 & 25,5 & 5,7 & 5,0 \\
\hline$\beta$-Alanine & 0,6 & 4,1 & 21,2 & 5,0 & 4,3 \\
\hline Hydroxylysine & 0,2 & 1,8 & 26,8 & 4,3 & 6,7 \\
\hline Methyllysine & 0,0 & 2,7 & 13,5 & 3,4 & 2,9 \\
\hline Sarcosine & 0,0 & 1,8 & 6,1 & 2,2 & 1,3 \\
\hline$\alpha$-Aminopimelic-acid & 0,0 & 0,1 & 11,3 & 0,9 & 2,5 \\
\hline
\end{tabular}

Thirty eight amino acids were identified and quantified in the cheetah urine samples, as shown in Table 3. Arginine was excreted at the highest mean concentration $(740 \mu \mathrm{mol} / \mathrm{L})$, followed by glutamine $(437.1 \mu \mathrm{mol} / \mathrm{L})$, alanine $(397.1 \mu \mathrm{mol} / \mathrm{L})$ and serine $(331.1 \mu \mathrm{mol} / \mathrm{L})$. As in the serum amino profiles, there were no significant differences in urine amino acid concentrations between male and female cheetahs. The fractional excretions (\%FE) of the amino acids are shown in Table 4 . The mean $\%$ FE of cystine was by far the highest at $21.92 \%$, followed by hydroxylysine $(6.34 \%)$, proline-hydroxyproline $(5.49 \%), \alpha$-aminopimelic acid $(4.89 \%), \beta$ - alanine $(4.05 \%), \alpha-$ aminoadipic acid $(3.98 \%)$, sarcosine $(2.86 \%)$, cystathionine $(2.41 \%)$ and glycine-proline $(1.74 \%)$. The fractional excretion percentages of the remaining amino acids were all less than $1 \%$.

Both urinary glycine and proline-hydroxyproline concentrations decreased significantly with age $(r=-0.50, \mathrm{p}=$ 0.009 and $r=-0.41, \mathrm{p}=0.02$ respectively) as shown in Figure 2. None of the serum and urine concentrations of individual amino acids correlated significantly with each other. 
Figure 1. Scatterplots and linear regression showing the significant correlations between age and 5 serum amino acids in cheetahs. Glycine $(r=-0.56, \mathrm{p}=0.0001)$, serine $(r=-0.36, p=0.02)$, proline $(r=-0.41, p=0.007)$, prolylproline $(r=-0.44, p=0.004)$ and hydroxyproline $(r=-0.44, p=0.003)$

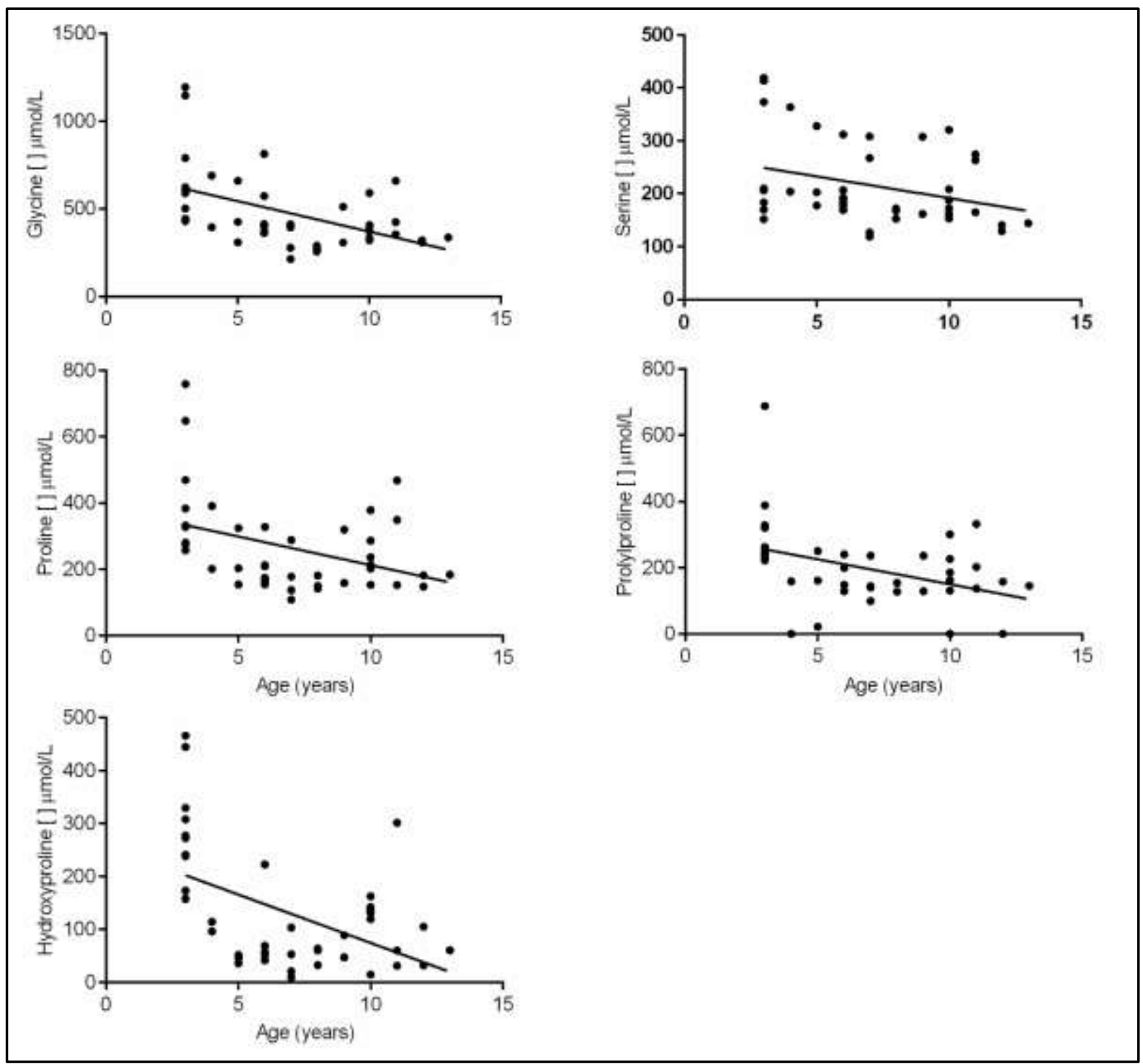

Figure 2. Scatterplots and linear regressions showing the relationship between age and urinary excretion of glycine $(r=-0.50, \mathrm{p}=0.009)$ and proline-hydroxyproline $(r=-0.46, \mathrm{p}=0.02)$.

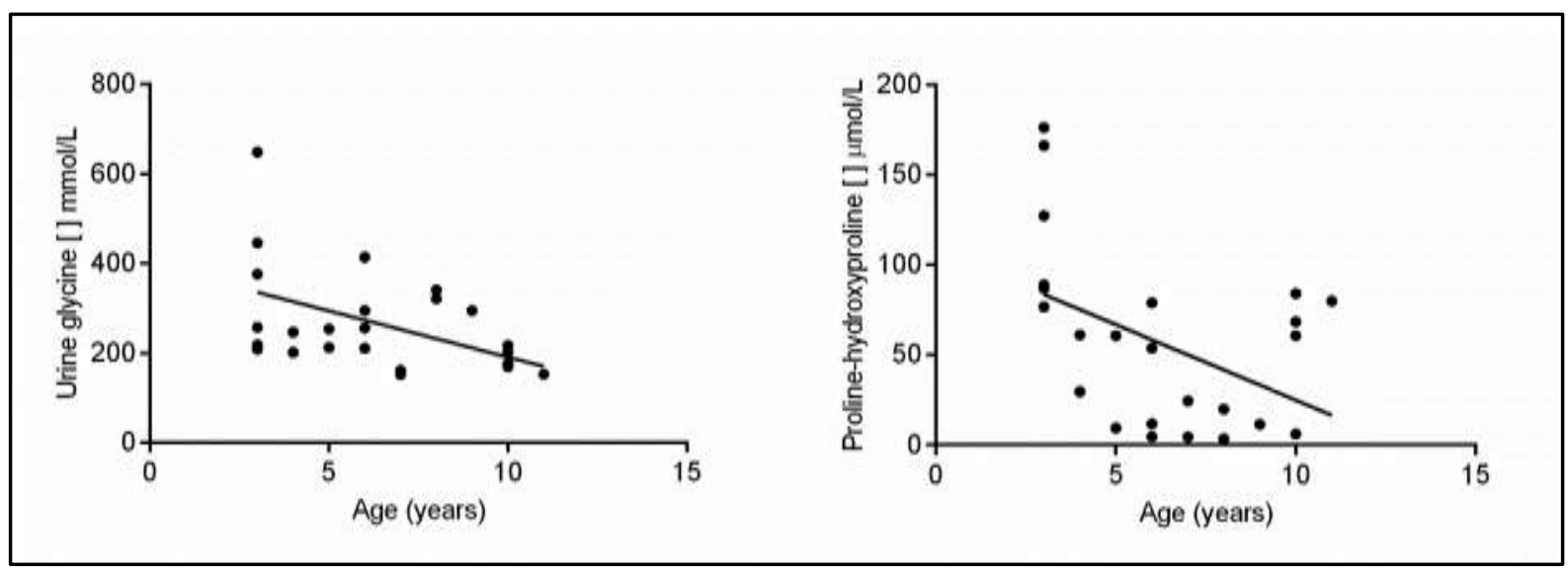


Table 3. Summary of the urine amino acid concentration data corrected to specific gravity in 26 adult cheetahs, listed in order from highest mean concentration to lowest $(\mu \mathrm{mol} / \mathrm{L})$.

\begin{tabular}{|c|c|c|c|c|c|}
\hline Amino acid & Minimum & Median & Maximum & Mean & Std. Deviation \\
\hline Arginine & 295.3 & 640.8 & 2265.0 & 740.0 & 372.2 \\
\hline Glutamine & 179.8 & 426.3 & 782.3 & 437.1 & 153.1 \\
\hline Alanine & 181.7 & 373.1 & 989.5 & 397.1 & 179.6 \\
\hline Serine & 191.7 & 331.1 & 605.2 & 331.3 & 81.9 \\
\hline Glycine & 152.2 & 232.8 & 648.8 & 270.7 & 117.4 \\
\hline Cystine & 96.62 & 230.7 & 636.1 & 245.1 & 129.8 \\
\hline Tryptophan & 92.9 & 164.8 & 358.2 & 181.9 & 62.0 \\
\hline Lysine & 85.1 & 145.4 & 298.7 & 156.2 & 51.9 \\
\hline Asparagine & 43.1 & 114.5 & 353.9 & 124.0 & 61.9 \\
\hline Valine & 26.1 & 62.5 & 493.0 & 95.0 & 106.1 \\
\hline Glutamic acid & 57.3 & 91.4 & 180.9 & 91.4 & 26.7 \\
\hline Threonine & 53.5 & 84.5 & 165.0 & 90.0 & 25.3 \\
\hline Histidine & 46.7 & 81.2 & 197.7 & 84.2 & 29.1 \\
\hline Ornithine & 22.1 & 52.2 & 282.9 & 70.3 & 60.9 \\
\hline 3-Methylhistidine & 13.7 & 52.0 & 191.1 & 69.6 & 53.8 \\
\hline$\alpha$-Aminoadipic acid & 2.9 & 41.2 & 176.0 & 64.1 & 55.0 \\
\hline Tyrosine & 33.0 & 57.5 & 108.2 & 61.5 & 19.9 \\
\hline Proline-hydroxyproline & 3.4 & 60.7 & 176.3 & 57.2 & 48.8 \\
\hline Cystathionine & 12.5 & 24.3 & 376.4 & 48.3 & 76.7 \\
\hline Pyroglutamic acid & 20.0 & 44.8 & 75.4 & 43.6 & 14.8 \\
\hline Proline & 10.7 & 28.0 & 218.7 & 41.0 & 41.4 \\
\hline Citrulline & 22.9 & 33.7 & 61.1 & 36.0 & 8.2 \\
\hline Aspartic acid & 16.6 & 27.5 & 110.8 & 32.9 & 19.1 \\
\hline Leucine & 15.5 & 25.1 & 70.2 & 28.8 & 12.1 \\
\hline$\beta$-Alanine & 7.4 & 25.0 & 77.0 & 28.4 & 17.7 \\
\hline allo-Isoleucine & 14.3 & 24.7 & 66.0 & 27.2 & 11.4 \\
\hline Phenylalanine & 13.4 & 24.5 & 49.4 & 26.1 & 8.7 \\
\hline Methionine & 13.5 & 25.0 & 38.1 & 25.3 & 6.8 \\
\hline Hydroxylysine & 1.5 & 13.6 & 96.1 & 21.9 & 24.0 \\
\hline Glycine-Proline & 5.4 & 15.7 & 31.3 & 15.6 & 6.2 \\
\hline Isoleucine & 7.6 & 13.7 & 33.0 & 15.1 & 6.3 \\
\hline Prolylproline & 0.0 & 1.4 & 203.0 & 10.9 & 39.9 \\
\hline Diaminopimelic acid & 0.0 & 0.0 & 70.9 & 10.0 & 19.3 \\
\hline$\alpha$-Aminobutyric acid & 3.3 & 6.2 & 42.4 & 9.3 & 9.0 \\
\hline Cystine-Homocystine & 0.0 & 4.2 & 79.4 & 9.2 & 17.4 \\
\hline Sarcosine & 0.0 & 4.6 & 36.5 & 6.9 & 7.8 \\
\hline$\alpha$-Aminopimelic acid & 0.2 & 1.2 & 10.2 & 1.6 & 1.9 \\
\hline
\end{tabular}


Table 4. Summary of the fractional excretion (FE\%) of amino acids in 20 adult cheetahs, listed in order from highest to lowest.

\begin{tabular}{|c|c|c|c|c|c|}
\hline Amino acid & Minimum & Median & Maximum & Mean & Std. Deviation \\
\hline Cystine & 4.55 & 20.24 & 54.81 & 21.92 & 13.99 \\
\hline Hydroxylysine & 0.07 & 3.11 & 21.39 & 6.34 & 6.73 \\
\hline Proline-hydroxyproline & 0.02 & 2.04 & 21.98 & 5.49 & 6.60 \\
\hline$\alpha$-Aminopimelic-acid & 0.02 & 3.36 & 22.37 & 4.89 & 5.86 \\
\hline$\beta$-Alanine & 0.34 & 2.84 & 10.26 & 4.05 & 3.10 \\
\hline$\alpha$-Aminoadipic-acid & 0.25 & 2.83 & 10.37 & 3.98 & 3.47 \\
\hline Sarcosine & 0.30 & 0.90 & 18.17 & 2.86 & 4.37 \\
\hline Cystathionine & 0.11 & 0.80 & 14.02 & 2.41 & 4.34 \\
\hline Glycine-Proline & 0.12 & 0.41 & 12.71 & 1.74 & 3.43 \\
\hline Asparagine & 0.31 & 0.76 & 2.70 & 0.88 & 0.50 \\
\hline Tryptophane & 0.14 & 0.58 & 2.12 & 0.76 & 0.56 \\
\hline Serine & 0.26 & 0.63 & 1.47 & 0.72 & 0.34 \\
\hline Arginine & 0.19 & 0.35 & 3.02 & 0.60 & 0.72 \\
\hline Aspartic-acid & 0.14 & 0.40 & 1.74 & 0.49 & 0.36 \\
\hline Lysine & 0.14 & 0.36 & 1.53 & 0.42 & 0.31 \\
\hline Ornithine & 0.04 & 0.32 & 0.96 & 0.40 & 0.27 \\
\hline Citrulline & 0.16 & 0.30 & 0.83 & 0.38 & 0.19 \\
\hline Tyrosine & 0.09 & 0.33 & 0.85 & 0.37 & 0.21 \\
\hline$\alpha$-Aminobutyric-acid & 0.06 & 0.13 & 2.12 & 0.31 & 0.49 \\
\hline Alanine & 0.06 & 0.25 & 1.32 & 0.29 & 0.27 \\
\hline Histidine & 0.07 & 0.24 & 0.88 & 0.28 & 0.20 \\
\hline Threonine & 0.09 & 0.28 & 0.55 & 0.28 & 0.12 \\
\hline Valine & 0.04 & 0.12 & 1.89 & 0.25 & 0.41 \\
\hline Glutamic-acid & 0.08 & 0.24 & 0.57 & 0.25 & 0.12 \\
\hline Glycine & 0.10 & 0.26 & 0.40 & 0.25 & 0.08 \\
\hline Phenylalanine & 0.06 & 0.17 & 0.45 & 0.21 & 0.11 \\
\hline Methionine & 0.07 & 0.19 & 0.35 & 0.19 & 0.07 \\
\hline Pyroglutamic-acid & 0.05 & 0.13 & 0.21 & 0.13 & 0.04 \\
\hline Glutamine & 0.04 & 0.12 & 0.19 & 0.12 & 0.04 \\
\hline Isoleucine & 0.03 & 0.07 & 0.16 & 0.08 & 0.04 \\
\hline Leucine & 0.03 & 0.08 & 0.16 & 0.08 & 0.03 \\
\hline allo-Isoleucine & 0.03 & 0.07 & 0.16 & 0.08 & 0.03 \\
\hline Proline & 0.02 & 0.06 & 0.24 & 0.07 & 0.05 \\
\hline Prolylproline & 0.00 & 0.01 & 0.14 & 0.02 & 0.04 \\
\hline Hydroxyproline & 0.00 & 0.00 & 0.01 & 0.00 & 0.00 \\
\hline
\end{tabular}

\section{DISCUSSION}

Serum or plasma amino acid profiles of large felids have, to our knowledge, not been reported in the literature. Serum alanine, lysine, ornithine and cystine values have been reported in a small number of caracals (Caracal caracal) and in all cases the concentrations were lower than those of the cheetahs in the present study (Tordiffe et al. 2012). With the exception of asparagine and threonine, the cheetah serum amino acid concentrations were also generally higher than plasma values reported in domestic cats (Heinze et al. 2009). Serum arginine and 
ornithine concentrations were substantially higher in cheetahs than in cats, with a 7.1 and 5.2 -fold difference respectively. Alanine, glutamic acid, glutamine, hydroxyproline, lysine, tryptophan and citrulline were approximately twice as high in cheetah serum.

In most carnivorous species, blood amino acid concentrations appear to be carefully regulated, but in the postprandial period and during longer periods of fasting ( $>2$ days), larger variations have been noted (Mustonen et al. 2005). Arginine is considered an essential amino acid in carnivores as it is required in large quantities for conversion to ornithine, which in turn is required for ammonia detoxification in the urea cycle. Arginine is also required for creatine and nitric oxide synthesis (Tapiero et al. 2002). In domestic cats, a single arginine-free meal is known to result in severe, potentially fatal hyperammonaemia (Morris and Rogers 1978). It appears that cats have a limited ability to synthesize arginine de novo from glutamate and glutamine via citrulline and ornithine in the intestinal mucosa due to reduced activity of pyroline-5-carboxylate synthase and ornithine aminotransferase (Morris 2002). Fortunately, arginine is replete in most animal tissues and under normal dietary conditions arginine deficiencies are unlikely to occur. Most large felids, like the cheetah, feed infrequently, consuming large quantities of food relative to their body size. It may therefore be necessary for large felids to maintain large serum arginine and or ornithine reserves to deal with the acute ammonia load resulting from such a large protein meal.

Five serum amino acid concentrations declined significantly relative to age in the cheetahs. These include serum glycine, serine, proline, prolylproline and hydroxyproline. Similar negative correlations for urine glycine and proline-hydroxyproline relative to age were demonstrated. The concentrations of these amino acids in some of the three-year-old cheetahs however appear to skew the data and if the data points of these three animals are removed, then the correlations are no longer significant. The higher concentrations of these related metabolites in urine and serum samples are, however, interesting. Hydroxyproline is present almost exclusively in collagen and is not reutilised for collagen synthesis once it is broken down. Urine excretion of both free and peptide-bound hydroxyproline is therefore thought to reflect the breakdown of mature collagen (Dull and Henneman 1963). Both glycine and proline are also found at high concentrations in collagen. Urine hydroxyproline concentrations are often used to evaluate bone collagen metabolism in conditions like osteoporosis and osteomalacia (Delmas et al. 2000). Since metabolic bone disease and nutritional secondary hyperparathyroidism are commonly diagnosed in young growing large felids, due to either reduced calcium intake and/or hypovitaminosis D (Fowler 1986), it is possible that elevated hydroxyproline in these younger animals may result from subclinical nutritional deficiencies. At three years of age cheetahs are, however, sexually and skeletally mature and ideally serum and urine samples should be evaluated in younger animals that are still growing.

Comparison of the urinary amino acid excretion profiles in cheetahs to those of other species is made difficult by the scarcity of studies in which quantitative urine amino acid data are reported, and by the fact that such studies generally report either $24-\mathrm{hr}$ excretion values or creatinine corrected values. The proportional amino acid excretion patterns, however, provide some information for comparison. In domestic dogs alanine is the amino acid excreted at the highest concentration in urine, followed by aspartate, leucine, serine, lysine and glycine (Hoppe et al. 1993). In contrast, arginine was by far the most abundant amino acid in the cheetah urine at a mean concentration almost twice that of alanine. Other amino acids, ranking higher on the list compared to dogs included tryptophan and cystine. Felinine, the sulphur-containing amino acid frequently detected at high concentrations in domestic cats and other felid species (Hendriks et al. 1995) was not detected in any of the cheetah samples. 3Methylhistidine, detected at high concentration in domestic cat urine (Worden et al. 1960), was only found at moderate concentrations relative to some of the other amino acids in the cheetahs.

In healthy humans, more than $99 \%$ of the free amino acids are reabsorbed by the renal proximal tubules, resulting in fractional excretions of less than $1 \%$ of circulating amino acids (Albanese and Orto 2012). In the immediate postprandial period, amino acid excretion increases dramatically, but returns to baseline levels approximately 5 hours after a meal (McMenamy et al. 1960). The fractional excretion of dipeptides and modified amino acids is generally higher than that of standard free amino acids (Silber and Porter 1949), possibly due to the lack of dedicated renal tubular transport mechanisms for these molecules. In the cheetahs, the dibasic amino acid cystine, had the highest fractional excretion of all the amino acids. The fractional excretion of cystine in cheetahs appears to be similar to those we previously recorded in healthy caracals (Tordiffe et al. 2012). In wild felids, it is possible that only dedicated transmembrane transport mechanisms exist for cystine. It is likely that the high metabolic demands for cystine - for production of glutathione, taurine, co-enzyme A and general protein synthesis in felids - are easily met by the methionine and serine provided in animal tissues. The relatively high urinary excretion of cystine, together with increased activity of hepatic cysteine dioxygenase, may therefore limit the risk of cystine toxicity in these animals (Stipanuk et al. 2006). 
A limitation of this study is that samples were collected from a single population of captive cheetahs that are fed a diet of horse or donkey meat. Ideally samples should be evaluated from other captive facilities that feed different diets, as well as from free-ranging cheetahs. Nevertheless, this study provides some foundational information on the serum and urine amino acid profiles of healthy captive cheetahs. Further research on the dynamic changes in serum amino acids after a typical meal should be evaluated and studies on the impact of dietary differences on the amino acid profiles in this species are warranted.

\section{ACKNOWLEDGMENTS}

We would like to thank all the staff at the AfriCat Foundation for their support and assistance with the project. We would also like express our gratitude to Mr Jano Jacobs and Mrs Ansie Mienie for their assistance with the processing and analysis of the samples.

\section{COMPLIANCE WITH ETHICAL STANDARDS}

Funding: This work was supported by the AfriCat Foundation and North West University.

Conflict of Interest: The authors declare that they have no conflicts of interest.

Ethical approval: The project was approved by the National Zoological Gardens of South Africa's Research and Ethics Committee (Project no. P11/07). A research/collecting permit (1846/2013) was obtained from the Namibian Ministry of Environment and Tourism and the samples were imported into South Africa with the required CITES export (no.0042838) and import (no. 137670) permits, as well as a veterinary import permit (no. 13/1/1/30/2/10/6-2013/11/002397). Once in South Africa, the samples were transported and stored with the required national Threatened or Protected Species (TOPS) ordinary permit (no. 05238).

\section{REFERENCES}

Albanese AA, Orto LA (2012) Urinary Excretion of Amino Acids 1. Elsevier

Armstrong MD, Stave U (1973) A study of plasma free amino acid levels. III. Variations during growth and aging. Metabolism 22:571-578.

Azuma K, Osaki T, Tsuka T, et al (2012) Plasma free amino acid profiles of canine mammary gland tumors. J Vet Sci 13:433-436. doi: 10.4142/jvs.2012.13.4.433

Blazer-Yost B, Jezyk PF (1979) Free amino acids in the plasma and urine of dogs from birth to senescence. Am J Vet Res 40:832-838.

Chan DL, Rozanski EA, Freeman LM (2009) Relationship among plasma amino acids, C-reactive protein, illness severity, and outcome in critically ill dogs. J Vet Intern Med 23:559-563. doi: 10.1111/j.19391676.2009.0296.x

Datta SP, Harris H (1952) Urinary amino-acid patterns of some mammals. Ann Eugen 17:107-116.

Delmas PD, Eastell R, Garnero P, et al (2000) The use of biochemical markers of bone turnover in osteoporosis. Osteoporos Int 11:S2--S17.

Deng P, Jones JC, Swanson KS (2014) Effects of dietary macronutrient composition on the fasted plasma metabolome of healthy adult cats. Metabolomics 10:638-650.

Dull TA, Henneman PH (1963) Urinary hydroxyproline as an index of collagen turnover in bone. N Engl J Med 268:132-134. 
Evered DF (1967) Species differences in amino acid excretion by mammals. Comp Biochem Physiol 23:163171.

Fowler ME (1986) Metabolic bone disease. In: Zoo and Wild Animal Medicine, WB Saunders Co.(2 nd Ed), Philadelphia, USA. pp 69-90

Hall WL, Millward DJ, Long SJ, Morgan LM (2003) Casein and whey exert different effects on plasma amino acid profiles, gastrointestinal hormone secretion and appetite. Br J Nutr 89:239-248.

Hanssen I, Lunde H, Gjessing LR (1989) Plasma amino acids in dogs with osteochondrosis or hip dysplasia. Acta Vet Scand 30:111-112.

Hargrove DM, Rogers QR, Calvert CC, Morris JG (1988) Effects of dietary excesses of the branched-chain amino acids on growth, food intake and plasma amino acid concentrations of kittens. J Nutr 118:311-320.

Heinze CR, Larsen JA, Kass PH, Fascetti AJ (2009) Plasma amino acid and whole blood taurine concentrations in cats eating commercially prepared diets. Am J Vet Res 70:1374-1382. doi: 10.2460/ajvr.70.11.1374

Hendriks WH, Moughan PJ, Tarttelin MF, Woolhouse AD (1995) Felinine: a urinary amino acid of Felidae. Comp Biochem Physiol Part B Biochem Mol Biol 112:581-588.

Hoppe A, Denneberg T, Jeppsson JO, Kagedal B (1993) Urinary excretion of amino acids in normal and cystinuric dogs. Br Vet J 149:253-268. doi: 10.1016/S0007-1935(05)80171-X

Longenecker JB, Hause NL (1959) Relationship between plasma amino acids and composition of the ingested protein. Arch Biochem Biophys 84:46-59.

McMenamy RH, Lund CC, Neville GJ, Wallach DF (1960) Studies of unbound amino acid distributions in plasma, erythrocytes, leukocytes and urine of normal human subjects. J Clin Invest 39:1675-1687. doi: 10.1172/JCI104191 [doi]

Miller RC, Brindle E, Holman DJ, et al (2004) Comparison of specific gravity and creatinine for normalizing urinary reproductive hormone concentrations. Clin Chem 50:924-932. doi: 10.1373/clinchem.2004.032292

Milsom JP, Morgan MY, Sherlock S (1979) Factors affecting plasma amino acid concentrations in control subjects. Metabolism 28:313-319.

Morris JG (2002) Idiosyncratic nutrient requirements of cats appear to be diet-induced evolutionary adaptations. Nutr Res Rev 15:153-168. doi: 10.1079/NRR200238

Morris JG, Rogers QR (1978) Ammonia intoxication in the near-adult cat as a result of a dietary deficiency of arginine. Science 199:431-432.

Munson L, Nesbit JW, Meltzer DGA, et al (1999) Diseases of captive cheetahs (Acinonyx jubatus jubatus) in South Africa: a 20-year retrospective survey. J zoo Wildl Med 30:342-347. doi: 10.2307/20095876

Munson L, Terio KA, Worley M, et al (2005) Extrinsic factors significantly affect patterns of disease in freeranging and captive cheetah (Acinonyx jubatus) populations. J Wildl Dis 41:542-548. doi: 10.7589/0090$3558-41.3 .542$

Mustonen A-M, Puukka M, Pyykönen T, Nieminen P (2005) Adaptations to fasting in the American mink (Mustela vison): Nitrogen metabolism. J Comp Physiol B Biochem Syst Environ Physiol 175:357-363. doi: 10.1007/s00360-005-0492-2

Okame R, Nakahara K, Murakami N (2015) Plasma amino acid profiles at various reproductive stages in female rats. J Vet Med Sci 77:815-821.

Rogers QR, Morris JG (1979) Essentiality of amino acids for the growing kitten. JNutr 109:718-723. 
Silber RH, Porter CC (1949) Urinary excretion of amino acids and peptides by dogs fed protein hydrolysates or amino acids. JNutr 38:155-164.

Stipanuk MH, Caudill MA (2013) Biochemical, physiological, and molecular aspects of human nutrition. Elsevier Health Sciences

Stipanuk MH, Dominy JE, Lee J-I, Coloso RM (2006) Mammalian cysteine metabolism: New insights into regulation of cysteine metabolism 1,2. 1652-1659.

Tapiero H, Mathe G, Couvreur P, et al (2002) I. Arginine. Biomed Pharmacother 56:439-445. doi: 10.1016/S0753-3322(02)00284-6

Tarttelin MF, Hendriks WH, Moughan PJ (1998) Relationship between plasma testosterone and urinary felinine in the growing kitten. Science 65:83-87.

Tordiffe ASW, Van Der Watt GF, Reyers F, et al (2012) Cystine urolithiasis in a caracal (Caracal caracal). J Zoo Wildl Med 43:649-651. doi: 10.1638/2011-0236R1.1

Tordiffe ASW, van Reenen M, Reyers F, Mienie LJ (2017) Gas chromatography-mass spectrometry profiles of urinary organic acids in healthy captive cheetahs (Acinonyx jubatus). J Chromatogr B Anal Technol Biomed Life Sci 1049-1050:8-15. doi: 10.1016/j.jchromb.2017.02.018

Tordiffe ASW, Wachter B, Heinrich SK, et al (2016) Comparative serum fatty acid profiles of captive and freeranging cheetahs (Acinonyx jubatus) in Namibia. PLoS One 11:e0167608. doi: 10.1371/journal.pone.0167608

Worden AN, Waterhouse CE, Sellwood EHB (1960) Studies on the composition of normal cat urine. J Small Anim Pract 1:11-23. 